\title{
What similarities can municipalities experience in crisis management?
}

\author{
A.S. Nilsen \\ Department of engineering and safety. Faculty of science and technology. UiT. The Arctic University in \\ Norway.
}

\begin{abstract}
Municipalities have an important role in crisis management. The Norwegian emergency principles of responsibility, parity and proximity are central, and the government expects municipalities to take care of crises in their area in accordance with the civil protection law. Due to the varying natures of different crises, one can expect crisis management to take different paths. This paper challenges that viewpoint and looks for similarities in municipal crisis management. Theoretical guidelines on preparedness and evaluation of crisis management show some hallmarks, which can encourage uniform practice. Findings from interviews with key personnel in municipalities and a literature review give the conclusion that there are some similarities in municipal crisis management.
\end{abstract}

\section{INTRODUCTION}

Studies of municipalities in my own research (Nilsen, 2007, Nilsen, 2008, Nilsen, 2013, Nilsen and Olsen, 2004, Nilsen and Olsen, 2005, Nilsen and Olsen, 2007) and supervision of several master theses on risk and crisis management in municipalities (Gulbrandsen, 2013, Time, 2012, Torkelsen, 2012, Hansen, 2016), reveal some similarities in the management of crises. This is the starting point for this research.

Previous analyses of crisis management research literature have revealed some general similarities (Normandin and Therrien, 2016, Lalonde, 2004). Normandin and Therrien examined the complementarity of order and disorder connected with resilience and Lalonde examined archetypes in crisis management.

A crisis can be defined as; "a threat to core values, the safety of people, or the functioning of critical infrastructure that must be urgently addressed under conditions of deep uncertainty" (Rosenthal et al. 1989; Boin et al. 2005). There are different challenges according to the type of crisis and its extent and consequences. Some crises are natural disasters, others have social causes. Some crises are a bolt from the blue, others are results of latent conditions. With such variety one can expect crisis management to take different paths.

However, there are institutional prerequisites like laws, regulations and guidelines that act to unify crisis management paths. In an emergency plan, the minimum requirement according to Norwegian civil protection law (Law, 2010) is to have crisis management, a warning plan, an overview of resources, an evacuation plan, and a plan for informing the public. Perry and Lindell's guidelines for emergency planning processes can also be a prerequisite before a crisis occurs (Perry and Lindell, 2003).

Although there are many differences in crisis management, the focus of this paper is to search for similarities. The research question is; what similarities can be found in municipal crisis management? This is a preliminary work; further research needs to be done to map the relevance and extent in more municipalities.

\section{CONTEXT}

Municipalities (at least in Norway and Sweden) have responsibility for crisis management in their jurisdiction and geographical area. In Norway, there are 426 municipalities $(01.01 .2017)$ of which about $50 \%$ have 5,000 inhabitants or less. This means that many staff in emergency management positions do not have this as a full time responsibility. There are four main principles in the Norwegian crisis management system; responsibility, parity, proximity, and the requirement for cooperative measures. The first three principles are common with the Swedish crisis management system. "The first principle specifies that those responsible for an activity in normal conditions also have the responsibility during a crisis. The second principle states that the activities should, as far as possible, be organized and located in the same way during a crisis 
as they are under normal conditions. The third principle declares that crises should be managed at the lowest possible level" (Nilsson and Eriksson, 2008:36). The fourth principle about collaboration of resources between different levels was included after the solo terrorist attack in Norway on 22.07.2011 (77 dead due to the bombing of government buildings and shooting at a political youth camp on an island). This paper's empirical focus is on crises at the municipal and County Governor level. The County Governor is responsible for inspections of the emergency work in the municipalities in their area.

\section{THEORY}

\subsection{Crisis management}

A shorthand definition of crisis management is "management practices concerning non-routine phenomena and developments" (Rosenthal et al., 2001:15). In this section, we will examine surprises, different typologies, preparedness and crisis management.

\subsection{Varieties of surprise}

According to Brian J. Kylen cited in (Weick and Sutcliffe, 2001:36-38), there are at least five categories of the unexpected. The first is when phenomena occur as "a bolt from the blue", with no prior model or hint of what is coming. The second category is when a surprise "is recognized, but the direction of the expectation is wrong". The third category is when you know what will happen, but the timing is off. The fourth category is when the duration of the event is wrong and the fifth and final category when a phenomenon is expected, but its amplitude is not. All of these categories concern expectations that are not fulfilled by the unexpected event.

\subsection{Typology of crises}

Crises have been classified in different ways. $t$ 'Hart and Boin used timeframe ( $t$ 'Hart and Boin, 2001). Gundel has a matrix according to predictability and influence (Gundel, 2005:109). A crisis is predicable if "place, time or in particular the manner of its occurrence are knowable to at least a third competent party and the probability of occurrence is not to be neglected" and can be influenced "if responses to stem the tide or to reduce damages by antagonising the causes of a crisis are known and possible to execute" (Gundel, 2005:109). The matrix has four categories; conventional, unexpected, intractable and fundamental crises. Unexpected and fundamental crises occur seldom compared to conventional crises. This is a broad classification and can serve as a toolkit for decision makers. It also gives an indication of where influence can be difficult, e.g. an intractable crisis like global warming, where international collaboration is called for.

\subsection{Preparedness and community crises}

To be prepared for crises there is a need for emergency planning. Perry and Lindell based their ten guidelines for emergency planning processes on existing research (Perry and Lindell, 2003). They state that the relationship between planning, training and written plans is essential. The planning is a neverending process, which includes change, complexity and the ability to adapt to different situations. The following list summarises the ten guidelines for emergency planning.

The emergency planning has to:

1 Be based on accurate knowledge. Often by using risk and vulnerability analysis (RAV)

2 Encourage appropriate actions by emergency managers

3 Be flexible in response. Following principles rather than many specific details

4 Address inter-organisational coordination

5 Contain a multi-hazard approach between different external agents

6 Have a training component

7 Test different scenarios

8 Understand that planning is a continuous process

9 Understand that planning is done under conditions of conflicts and resistance

10 Acknowledge that planning and crisis management are two different functions

Planning in advance of a crisis is a state of readiness and community preparedness. Perry and Lindell also underline that small communities with few written plans are more reliant on personal relationships for handling incidents or crises. In bigger communities, more formalities are likely. Finally, they state that planning builds preparedness, but the actual crisis management is a different function.

\subsection{Management of crises}

Quarantelli has analysed the evaluation of the management of community disasters (Quarantelli, 1997). Although our focus is on crises, we can see some general features that can be of relevance; warnings, evacuation, sheltering, emergency medical care, protection of property, and search and rescue. In addition, coordination and restoring essential public services must be adequately carried out. The mobilisation of personnel and resources should be effective and the delegation of tasks and division of labour should be appropriate. There should be a good balance between emergent and established organisational behaviour. A 
well-functioning emergency operation centre is essential. The main point in the article is to have good management and be able to use the best tactics for handling the specific crisis that occurs.

\section{METHOD}

Two methods were used to find information about similarities in crisis management. A literature review and interviews.

\subsection{Search for research literature}

A database and journal search was conducted at the end of December 2016.

The search was to look for similarities in crisis management in municipalities/communities within the social sciences from 2004 and later, to find newer research than Perry and Lindell's review from 2003. The following search terms were used:

1 Municipality, crisis management, similar

2 Community, crisis management, similarity

The following were searched:

- Database Web of Science (16 hits), this resulted in 3 relevant articles, from the Journal of Risk Research and the Journal of Public Relations and Physical Geography.

- Scopus (34 hits), 2 of the same articles as in Web of Science were relevant.

- Journal of Contingencies and Crisis Management (70 hits), 10 articles were relevant.

This gave a total of 13 relevant articles.

The articles were assigned to one of two main categories for analysis; general findings or specific topics. This is further described in the results section.

\subsection{Interviews}

Interviews covering experiences and reflections about crisis management were conducted with key personnel in three municipalities and one representative from a County Governor (Nilsen, 2013). Two interviews were conducted after the 2013 report, one in 2013 and one in 2016. This gave six relevant interviews for analysing similarities and challenges in crisis management.

\section{RESULTS}

The presentation of the literature review comes first, thereafter the empirical findings.

\subsection{Research literature categories}

The general category covers reflections on crisis management as a whole. The specific category covers more detailed articles on specific elements.
Table 1. General articles.

\begin{tabular}{lll}
\hline Topic & Authors & Article Title \\
\hline Culture & $\begin{array}{l}\text { Alessio et al., } \\
2016\end{array}$ & $\begin{array}{l}\text { Risk cultures and dominant } \\
\text { approaches towards } \\
\text { disasters in seven European } \\
\text { countries }\end{array}$ \\
Archetypes & Lalonde, 2004 & $\begin{array}{l}\text { In search of archetypes in } \\
\text { crisis management }\end{array}$ \\
$\begin{array}{l}\text { Overall } \\
\text { coordination }\end{array}$ & $\begin{array}{l}\text { Boin and } \\
\text { Bynander, 2014 }\end{array}$ & $\begin{array}{l}\text { Explaining success and } \\
\text { failures in crisis coordina- } \\
\text { tion }\end{array}$ \\
Complexity & $\begin{array}{l}\text { Normandin and } \\
\text { Resilience factors recon- } \\
\text { ciled with complexity: The } \\
\text { dynamics of order and dis- } \\
\text { order }\end{array}$ \\
\hline
\end{tabular}

Table 2. Specific articles.

\begin{tabular}{lll}
\hline Topic & Authors & Article Title \\
\hline Collaboration & $\begin{array}{l}\text { Danielsson, 2016, } \\
\text { Ödlund, 2010 }\end{array}$ & $\begin{array}{l}\text { Following routines: A chal- } \\
\text { lenge in cross-sectorial col- } \\
\text { laboration. } \\
\text { Pulling the same way? A } \\
\text { multi-perspectivist study of } \\
\text { crisis cooperation in gov- } \\
\text { ernment. }\end{array}$ \\
& & Nilsson and Eriks- The role of the individual -
\end{tabular}
son, $2008 \quad$ A key to learning in preparedness organizations

Exercises Laere, 2013, Wandering through crisis Berlin and and everyday organizing; Carlström, 2015 Revealing the subjective nature of interpretive, temporal and organizational boundaries.

Collaboration exercises: What do they contribute?A study of learning and usefulness

$\begin{array}{lll}\begin{array}{l}\text { Crisis } \\ \text { information }\end{array} & \text { Heath et al, 2009 } & \begin{array}{l}\text { Crisis and risk approaches } \\ \text { to emergency management } \\ \text { planning and communica- } \\ \text { tion: The role of similarity } \\ \text { and sensitivity }\end{array} \\ \begin{array}{l}\text { Psychology } \\ \text { research }\end{array} & \begin{array}{l}\text { Enander et al., } \\ \text { 2015, Enander et } \\ \text { al., 2010 }\end{array} & \begin{array}{l}\text { Why worry? Motivation for } \\ \text { crisis preparedness work } \\ \text { among municipal leaders in } \\ \text { Sweden. } \\ \text { A tear in the social fabric: } \\ \text { Communities dealing with } \\ \text { socially generated crisis } \\ \text { Is crisis management (only) } \\ \text { a management of excep- } \\ \text { tions? }\end{array} \\ & & \end{array}$

\subsection{Findings from interviews}

\subsubsection{What do the municipalities have in common?} Every municipality in this study has risk and vulnerability analyses (RAV). They have a crisis staff and 
an emergency plan covering warning, evacuation, resource oversight, and informing the public. This is the minimum requirement in the civil protection law. The principles of responsibility, parity and proximity are foundation stones in how to organise Norwegian emergency preparedness. The main aim is to secure life and health for inhabitants in the municipality.

The county governor interview revealed that their county holds regular joint exercises with the municipalities. The County Governor's aim is to test the municipalities' emergency preparedness. The three municipalities confirmed that they have participated in such exercises. This shows that the municipalities carry out exercises on a regular basis.

One of the municipalities made a general plan for large incidents (crises). "For us it plays no role whether it is terror, sabotage, dangerous goods, a huge chain collision or extreme weather, for that matter. We made a plan for 7-8 large incidents (crises). This decided the capacity according to crisis planning and management".

\subsubsection{Common understanding of challenges in $\mathrm{mu}$ - nicipalities}

Norway has many small municipalities, which have limited resources and emergency planning competence. Although a municipality is small, it still has the same demands from governmental laws and regulations. One of the municipalities underlined the difficult balance between using many resources to plan for a crisis, when the likelihood of occurrence is very small. The municipalities in this study still find coordination with external institutions a bit challenging.

Huge and unexpected crises are challenging to both plan for and tackle. "We can tackle $80 \%$, but the remaining $20 \%$ will be beyond our scope of experience" - quote from emergency leader. This shows an awareness about the unexpected.

\subsubsection{Positive experiences}

One of the municipalities evaluated their long time experience in working with emergency planning and incident handling. They found that they improved communication with their inhabitants, they had a better foundation for decisions, they had good map solutions and had improved coordination with others.

The ability to act is a hallmark for many of the small municipalities. Although their plans might be incomplete, they have good control of human and material resources in a crisis. This impressed the County Governor who was interviewed.

The crisis management staff's understanding is that as long as the municipality is prepared, has completed exercises and has a good emergency plan, there are more similarities than differences in municipal crisis management.

\section{DISCUSSION}

This paper focusses on the municipal and County Governor level. The focus is on crises and not disasters. The extent of a crisis is beyond everyday incidents handled by the main emergency services. We will first focus on similarities in practice and common challenges, thereafter elaborate theoretical dimensions.

\subsection{Similarities}

Every municipality deals with small incidents in everyday services, for instance leaking pipes, traffic incidents or fires. This means that they have some experience that can be of relevance in a crisis. Even if a crisis escalates, it is still related to ordinary services, but on a much larger scale. The Civil Protection law's prerequisites for emergency management and the four Norwegian principles for emergency preparedness have similarities to theory in emergency planning processes (Perry and Lindell, 2003) and hallmarks in crisis management (Quarantelli, 1997).

We will elaborate some of our empirical findings and connect to the relevant guidelines for emergency planning. Municipalities use risk and vulnerability analysis (RAV) as a tool to try to find accurate knowledge. Having oversight of all relevant data in a complex and changing environment is difficult, because it is not an area of instrumental rationality. Perry and Lindell recommend seeking for the best available knowledge, including using experts. The municipalities often use external experts in their RAVs to help with specific topics. However, having oversight over every possible incident or crisis that can occur is impossible, but it is important to seek new knowledge and be open for emerging signals.

The municipalities train on a regular basis. The emergency plan needs to be used in training to find weaknesses and uncover the need for updating. The internal coordination, roles, and responsibilities can also be tested. This training can be important when a crisis occurs, because they have experience using the plan.

Scenario planning is a way to think through challenges in advance. The municipalities in this study stated that most of the unwanted incidents or crises are handled in similar ways. They said that general principles like responsibility, parity and proximity are a way to a uniform response.

The main aim is to secure life and health of the inhabitants. Also to have an emergency plan which fulfills the requirements of the Civil Protection Law. Perry and Lindell state that guiding principles are better suited as prerequisites in a crisis than specific details. These give the ability to adapt to changing conditions.

A municipality is an organisation with a huge range of services. As we see in the findings, there is a 
dilemma using many resources to prepare for crises that may not happen. Small municipalities have resource constraints and may have a lack of competence. Perry and Lindell also state that emergency planning happens under conditions of conflict and resistance in use of resources.

Small communities/municipalities can handle crisis management without good written plans. The County Governor was impressed by some of the crisis handling in his area, because of the good overview of local resources and material. Here they were reliant on personal resources and informal relationships.

From the empirical findings, emergency leaders state that there are many similarities in crisis management. From the literature review, Laere has a hypothesis that "organizing in crisis and organizing in noncrisis in essence is more similar than different" (Laere, 2013:24). However, these similarities need to be researched further in order to find exactly what they involve and if they are relevant for a wide range of municipalities/communities.

Qurantelli discusses generic functions in crisis management as shown in the theory section, for example, warning, evacuation and restoring essential public services. Most of these hallmarks are prevalent in the civil protection law. These are foundations that can be used independent of the kind of crisis. From the specific topics in table 2, we see that many findings are similar to these hallmarks.

What we find is that preparedness and crisis management are two sides of the same coin. They are connected in that being prepared can better the quality of crisis management.

\subsection{Common challenges in municipal crisis management}

There are challenges related to the scale of a crisis. A major unexpected and unforeseen crisis can escalate into an uncontrollable situation. According to an emergency leader, the challenge is to think through unthinkable, worst-case scenarios in advance and to plan outside the comfort zone.

Another challenge is that private institutions like infrastructure companies are not required to have large-scale exercises together with municipalities and when a crisis occurs, they do not have coordinated experience. Boin and McConnel stress that it is necessary to make contact with private institutions before a crisis occurs, to be better prepared (Boin and McConnel, 2007).

\subsection{The general category in crisis management}

We can sort the articles in table one into three subcategories; cultural theory, strategic crisis management and complexity theory.
The dominant approaches in cultural theory are individual, fatalistic and state-oriented based on sociocultural factors. The second subcategory maps archetypes in strategic crisis management as collectivist, integrators and reactive.

The last subcategory uses complexity theory, where Normadine and Therrien's reflections on the dynamics of order and disorder and Stacy's concepts of stability and chaos are relevant (Normandin and Therrien, 2016, Stacy, 1993). Complexity theory is often described as a set of contradictions, and in our material some of these are; order and disorder, predictability or not, influence or not, top-down or bottom-up coordination, bureaucracy or dynamic organising and the difference between a fixed plan and a continual planning process.

We often see that crisis management is not either or, but a combination of factors that need to be considered. It is a form of contextual rationality, e.g. where some elements from emergency plans can be considered of relevance in a crisis and others not. If we consider coordination, a solution can be collaborative crisis organising that builds on both bottom-up and top-down strategies. Boin and Bynander stress that there is a need for more research to see how these contradictions can reinforce each other (Boin and Bynander, 2014).

To create order out of chaos we can consider some of Stacy's recommendations that can be relevant in learning to improve crisis management (Stacy, 1993). 1 Managers can encourage self-organising groups under crises. We find this hallmark in HROs, where during a crisis there is a shift from a hierarchical organisation to a flat organisational structure, where the experts handle the crisis at hand.

2 Managers can present ambiguous challenges. This is to enforce a variety of solutions. Exposing a crisis team to challenging situations can be a way to "think through the unthinkable", as described in the "Common challenges" section above.

3 Improving group-learning skills can be of relevance in enabling a crisis staff to better function together in a crisis.

These reflections are a starting point to be further elaborated.

\section{CONCLUSION}

What we see is that crisis management is not only a management of exceptions as suggested by RouxDufort (Roux-Dufort, 2007). There are some similarities in crisis management due to the prerequisites for emergency planning and crisis management theory presented above. Some of these recommendations are found in our study of municipalities. At the empirical level, the crisis management staff's understanding is that as long as the municipality is prepared, has completed exercises and has a good emergency plan, there 
are more similarities than differences in municipal crisis management. These similarities should be further researched as a matter of importance.

Having some similarities in crisis management can raise the confidence of the individuals performing in a crisis, but it must be balanced with awareness of the unexpected.

\section{REFERENCES}

Alessio, C., Dressel, K. \& Pfeil, P. 2016. Risk cultures and dominant approaches towards disasters in seven European countries. Journal of Risk Research, 19, 288-304.

Berlin, J. M. \& Carlström, E. D. 2015. Collaboration exercises: What do they contribute?- A study of learning and usefulness. Journal of Contingencies and Crisis Management, 23, 11-23.

Boin, A. \& Bynander, F. 2014. Explaining success and failures in crisis coordination. Series A Physical Geography.

Boin, R. A. \& Mcconnel, A. 2007. Preparing for critical infrastructure breakdowns. Journal of Contingencies and Crisis Management, 15, 50-59.

Danielsson, E. 2016. Following routines: A challenge in crosssectorial collaboration. Journal of Contingencies and Crisis Management, 24, 36-45.

Enander, A., Hede, S. \& Lajksjö, Ô. 2015. Why worry? Motivation for crisis preparedness work among municipal leaders in Sweden. Journal of Contingencies and Crisis Management, 23, 1-10.

Enander, A., Lajksjö, Ô. \& Tedfeldt, E. L. 2010. A tear in the social fabric: Communities dealing with socially generated crises. Journal of Contingencies and Crisis Management, 18, 39-47.

Gulbrandsen, E. 2013. Samvirke som katalysator for kommunale ROS-analyser. Master thesis, Universitetet i Stavanger og Universitetet i Tromsø.

Gundel, S. 2005. Towards a new typology of crisis. Journal of Contingencies and Crisis Management, 13, 106-115.

Hansen, L. R. 2016. To expect the unexpected - Mission impossible? En studie om beredskapsplanlegging, beredskapsarbeid og uventede hendelser. Master, Uit The Arctic University in Norway.

Heath, R. L., Lee, J. \& Lan, N. 2009. Crisis and risk approaches to emergency management planning and communication: The role of similarity and sensivity. Journal of Public Relations Research, 21, 123-141.

Laere, J. V. 2013. Wandering through crisis and everyday organizing; Revealing the subjective nature of interpretive, temporal and organizational boundaries. Journal of Contingencies and Crisis Management, 21, 17-25.

Lalonde, C. 2004. In search of archetypes in crisis management. Journal of Contingencies and Crisis Management, 12.

Law 2010. Civil Protection Act. https://lovdata.no/.

Nilsen, A. S. 2007. Municipal risk management. Implications and the use of different risk tools. $\mathrm{PhD}$, Universitetet i Stavanger http://brage.bibsys.no/uis/.

Nilsen, A. S. 2008. Tools for empowerment in local risk management. Safety Science, 46, 858-868.

Nilsen, A. S. 2013. Risikostyring i kommuner? En empirisk kartlegging av risikostyring og relaterte praksiser. Stavanger: DSB.

Nilsen, A. S. \& Olsen, O. E. 2004. Universal and contextual tools as a double strategy in emergency planning. International Journal of Emergency Management, 2, 81-97.

Nilsen, A. S. \& Olsen, O. E. 2005. Different strategies equal practice? Risk assessment and management in municipalities. Risk Management: An International Journal, 7, 37-47.
Nilsen, A. S. \& Olsen, O. E. 2007. Resistance or acceptance? Mitigation strategies in risk management. Risk Management: An International Journal, 9, 255-270.

Nilsson, J. \& Eriksson, K. 2008. The role of the individual. -A key to learning in preparedness organizations. Journal of Contingencies and Crisis Management, 16, 135-142.

Normandin, J.-M. \& Therrien, M.-C. 2016. Resilience factors reconciled with complexity: The dynamics of order and disorder. Journal of Contingencies and Crisis Management, 24, 107-118.

Perry, R. W. \& Lindell, M. K. 2003. Preparedness for emergency response: Guidelines for the emergency planning process. Disasters, 27, 336-350.

Quarantelli, E. L. 1997. Ten criteria for evaluating the management of community disasters. Disasters, 21, 39-56.

Rosenthal, U., Boin, R. A. \& Comfort, L. K. 2001. Managing crises, Illinois, Charles C Thomas Publisher, LTD.

Roux-Dufort, C. 2007. Is crisis management (only) a management of exceptions? Journal of Contingencies and Crisis Management, 15, 105-114.

Stacy, R. 1993. Strategy as order emerging from chaos. Long range planning, $26,10-17$.

T'Hart \& Boin, A. 2001. Between crisis and normalcy. The long shadow of post-crisis politics. In: Rosenthal, U., Boin, A. R. \& Comfort, L. (eds.) Managing crisis. Springfield, Illionois: Charles C. Thomas.

Time, I. 2012. ROS-analyse i kommunal arealplanlegging. Master, Universitetet i Stavanger.

Torkelsen, T. 2012. Risikopersepsjon - En studie av hvordan sentrale aktørers oppfatning av risiko kan påvirke helhetlig kommunal risiko- og sårbarhetsanalyser og de relaterte vurderinger som gjøres. Master, Universitetet i Stavanger.

Weick, K. E. \& Sutcliffe, K. M. 2001. Managing the unexpected, San Francisco, CA, Jossey- Bass

Ödlund, A. 2010. Pulling the same way? A multi-perspectivist study of crisis cooperation in government. Journal of Contingencies and Crisis Management, 18, 96-107. 